\title{
REPRESENTAÇÕES DA INFÂNCIA NA OBRA MACHADIANA: O MENINO É PAI DO HOMEM?
}

Fernanda Coutinho

Universidade Federal do Ceará

Fortaleza (CE), Brasil

\begin{abstract}
Resumo: Este artigo objetiva situar a presença da infância e da criança em alguns contos e romances de Machado de Assis. Partindose da ideia de que a infância é entendida como uma época fundamental da existência humana, pretende-se ressaltar a recuperação desse tempo via memória, como definidora do reconhecimento de si mesmo. Busca-se, ainda, com base no entendimento de que a escrita machadiana representou um exercício de interpretação da alma humana, verificar de que maneira o escritor situa a figura infantil face às atitudes que demandam o reconhecimento do outro. Por fim, por intermédio do pensamento de Machado de Assis, vertido em ficção, pretende-se mostrar como suas ponderações podem ajudar a melhor compreender as complexas questões que envolvem criança e infância em nossa contemporaneidade.
\end{abstract}

Palavras-chave: infância; criança; narrativa; costumes; contemporaneidade.

\section{Representations of childhood in Machado de Assis's work: is the child father of the man?}

\begin{abstract}
This article aims to situate the presence of children and of childhood itself in some of the short stories and novels by Machado de Assis. Based on the understanding of childhood as a fundamental time in human existence, it intends to emphasize the recovery of this time through memory, as a defining recognition of oneself; supported by the belief that the author's writings were an exercise of the human soul's interpretation, it pursues an understanding of how the writer places the child's figure in face of the attitudes that demand the recognition of the other. Finally, through the thought of Machado de Assis, translated in fiction, it intends to show how their arguments may be helpful to a better understanding of the complex issues surrounding children and childhood nowadays.
\end{abstract}

Keywords: childhood; child; narration; customs; nowadays. 
Das muitas sentenças escritas por Machado de Assis, uma, especialmente, sobressai pela aguda contundência com que chega à compreensão do leitor. Trata-se da derradeira frase do capítulo "Das negativas", presente nas Memórias póstumas de Brás Cubas. Reflexão do defunto autor ao chegar ao "outro lado do mistério", ${ }^{1}$ exprime ela, como se sabe, o resultado da contabilidade entre o deve e o haver das coisas deste mundo, com um leve desequilíbrio para o prato da balança que lhe daria um saldo, ainda que saldo pequeno: "- Não tive filhos, não transmiti a nenhuma criatura o legado da nossa miséria." 2

Súmula do proverbial pessimismo machadiano, diriam muitos. Contudo, as convicções, longe de serem únicas em si mesmas, são convites reiterados a interpretações discrepantes.

Paulo Mendes Campos, por exemplo, ao fazer a apologia da procriação, na irritada e ao mesmo tempo bem-humorada crônica "Meu reino por um pente", é estimulado nesse sentido pelo entusiasmo de um outro Machado - este mineiro -, o Aníbal: "Eu não sei por quê, Paulo, mas fazer filhos é o que há de mais importante." Movido por tal euforia, o cronista confessa afinal que, por conta disso, "foi descobrindo devagar a melancólica impostura daquelas palavras corrosivas". ${ }^{3}$

Assim, a partir do embate entre a crueza de um diagnóstico cáustico sobre o homem e uma mal disfarçada condescendência acerca dele, torna-se possível empreender uma discussão sobre a criança na obra do grande escritor brasileiro. De saída, algumas perguntas: que tratamento é dado por Machado de Assis não só à criança, como também ao sentido de "infância"? Terão essas duas variáveis a potência de plasmar verdades sobre a condição humana como tantos outros temas veiculados em suas páginas?

Em O enigma do olhar, Alfredo Bosi sintetiza uma verdade de ordem geral para a crítica que se vem debruçando sobre a vasta produção ficcional do escritor em

\footnotetext{
${ }^{1}$ ASSIS, Machado de. Obra completa. v. 1. Rio de Janeiro: Nova Aguilar, 1986. p. 639.

${ }^{2}$ Ibidem.

${ }^{3}$ CAMPOS, Paulo Mendes. Meu reino por um pente. In: 1981. p. 75-76. . Crônicas escolhidas. São Paulo: Ática,
} 
apreço, ao afirmar que a principal preocupação do romancista fluminense é o comportamento humano, acrescentando que "a originalidade de Machado está em ver por dentro o que o Naturalismo veria por fora". ${ }^{4}$ A partir da sugestão de Bosi, pretendese verificar como as coisas encobertas não passavam despercebidas ao escritor, que parecia munido de uma luneta de alcance, capaz de alargar o ângulo do qual via objetos distantes de si, parecendo aproximá-los de seu posto de observação. Essa sutileza de percepção não colocou à margem a criança, que é apresentada, em muitos casos, como protótipo das contradições do adulto que ela viria a ser um dia.

A presença infantil na obra machadiana é verificável desde 1866, ainda no Jornal das Famílias, onde aparece "Fernando e Fernanda", narrativa que, posteriormente, fará parte dos Contos recolhidos, compilação de R. Magalhães Júnior, publicada em $1956 .{ }^{5}$ Tem-se aí um relato em que está presente uma isotopia própria do ficcionista: o amor, acalentado na meninice entre quase irmãos, porém responsável, mais tarde, por dolorosos desenganos. Texto marcadamente romântico, em que ficam impressos os passos de alguém que só engatinha na arte de contar histórias, nele não se executa ainda um procedimento que lhe seria caro: dar corda para trás no relógio do tempo, trazendo de volta o passado, um passado coleante a se insinuar cavilosamente por entre os dias do presente. Para Lygia Fagundes Telles, nisso residiria a "sedução do texto [machadiano] onde há sempre um narrador obstinado tentando enfiar a criança na pele do adulto [...] Mas a criança também escamoteia, dissimula - e agora? Ainda assim, a busca prossegue aguda, como era ele (ou ela) bem antes disso tudo acontecer?" 6

A esse propósito, a obstinação de Bento Santiago quanto à traição de Capitu lança mão da memória da época de menino para sancionar o veredicto que era ao mesmo tempo desejado e indesejado - considerando-se o perfil ambivalente do personagem. Esse é bem o caso do capítulo XXXIII, em que o leitor toma conhecimento do episódio do penteado, o qual redundará na emoção assustada e feliz do primeiro

\footnotetext{
${ }^{4}$ BOSI, Alfredo. O enigma do olhar. São Paulo: Ática, 1999. p. 18.

${ }^{5}$ ASSIS, Machado de. Contos recolhidos. Prefácio e organização de Raimundo Magalhães Júnior. Rio de Janeiro: Civilização Brasileira, 1956.

6 TELLES, Lygia Fagundes. Apresentação de Machado de Assis. In: SECCHIN, Antonio Carlos; ALMEIDA, José Maurício Gomes de; SOUZA, Ronaldes de Melo e (Orgs.). Machado de Assis: uma revisão. Rio de Janeiro: In-Fólio, 1998. p. 12.
} 
beijo de ambos. Capitu, como se sabe, dá a esse gesto amoroso um disfarce irretocável, ante a desconfiança de sua mãe - atitude em visível contraste, aliás, com a vacilação mal contida de Bentinho. Interessa observar que o citado capítulo obedece a uma rígida convenção sintagmática, pois é precedido pela célebre reflexão em torno dos "olhos de ressaca". Esse trecho do livro passa a ter, assim, forte valor indicial, uma vez que representa uma das principais chaves de leitura para a composição do Otelo à brasileira.

Além disso, acena para os padrões de comportamento ditados pela voz da cultura, como explicitado por David Le Breton, ao enunciar que os

\begin{abstract}
ritos de interação são antes de tudo encenações ordenadas e inteligíveis de condutas individuais e sugerem um modo do corpo e da palavra para as trocas com o outro, uma definição do lícito e do ilícito no acesso ao corpo, de acordo com as circunstâncias. A obediência mútua a esses signos permite recuperar rapidamente qualquer violação às normas de conduta com um significado particular que só o contexto está habituado a distinguir. ${ }^{7}$
\end{abstract}

Como tal, o episódio demonstra também que, crianças que fossem Capitu e Bentinho, seu modo de agir repercutia o eco dessas ordenações.

Nesse romance de Machado de Assis, é certo que o fogo daquela emoção infantil não esmaece, pois o Bentinho da meninice continua a existir no Bento Santiago maduro que recorda seu primeiro beijo.

Pedi-lhe que levantasse a cabeça, podia ficar tonta, machucar o pescoço. Cheguei a dizer-lhe que estava feia; mas nem esta razão a comoveu.

- Levanta, Capitu!

Não quis, não levantou a cabeça e ficamos assim a olhar um para o outro, até que ela abrochou os lábios, eu desci os meus e... ${ }^{8}$

A cena, descrita com singular plasticidade, flagra ainda um ritual de ultrapassagem: o mundo da infância recuando diante do poder de Eros. Com este beijo o protagonista

\footnotetext{
${ }^{7}$ LE BRETON, David. Ritos de intimidade. In: CAHEN, Gérald (Coord.). O beijo: primeiras lições de amor, história, arte e erotismo. Tradução de Ana Matilde de Mesquita Sampaio. São Paulo: Mandarim, 1998. p. 69.

${ }^{8}$ ASSIS, Machado de. Obra completa. v. 1. Rio de Janeiro: Nova Aguilar, 1986, p. 844.
} 
desvenda o primeiro segredo da alquimia amorosa, o que a leva a repetir: "Sou homem!", 9 num misto de surpresa e de temor.

Experiências fundadoras na vida dos seres - tais como a do beijo - parecem estabelecer um pacto com a memória sentimental e se fixam com tal intensidade na sensibilidade, que nem o ímpeto destruidor do tempo não consegue arrancá-las daí, como mostra o discurso repassado de melancolia de Dom Casmurro:

Talvez abuso um pouco das reminiscências osculares; mas a saudade é isto mesmo; é o passar e repassar das memórias antigas. Ora, de todas as daquele tempo creio que a mais doce é esta, a mais nova, a mais compreensiva, a que inteiramente me revelou a mim mesmo. Outras tenho, vastas e numerosas, doces também, de vária espécie, muitas intelectuais, igualmente intensas. Grande homem que fosse, a recordação era menor que esta. ${ }^{10}$

A ideia de rito de passagem torna-se ainda mais pertinente se for relembrado que, antes, a proximidade entre os dois era pautada pela ideia do brincar, em que as bonecas figuravam como seres de mediação. Bentinho recorda toda uma mise-en-scène, típica da meninice, em que ele se transformava no médico das bonecas da vizinha: "Entrava no quintal dela com um pau debaixo do braço, para imitar o bengalão do doutor João da Costa; tomava o pulso à doente e pedia-lhe que mostrasse a língua. 'É surda, coitada!', exclamava Capitu." ${ }^{11}$ A aproximação das duas circunstâncias marca a distância entre os jogos do faz de conta, típicos da infância, e a competência para adequar-se aos jogos sociais por meio da simulação de outras realidades.

No que toca à criança, o sentido da dissimulação também se apresenta nas Memórias póstumas, sendo que aí toma ares mais buliçosos, através das peraltices do personagem-narrador: "esconder os chapéus das visitas, deitar rabos de papel a pessoas graves, puxar pelo rabicho das cabeleiras, dar beliscões nos braços das matronas"... ${ }^{12} \mathrm{O}$ relatar dessas experiências ligadas à ridicularização demonstra que, nessa crônica rememorativa de sua existência, o narrador esboça com frequência quadros de gênero,

\footnotetext{
${ }^{9}$ Idem, p. 845.

${ }^{10}$ Idem, p. 846.

${ }^{11}$ Idem, p. 822.

${ }^{12}$ Idem, p. 527.
} 
que são representações da vida cotidiana veiculadas pelo viés da ficção. Nela fica assim registrado um diagrama do modelo de convivência entre as classes sociais vigentes na corte do tempo do rei. Nesse diálogo entre ficção e história, o narrador se utiliza da arrogância da criança abastada para exibir toda a prepotência de um sistema que ignora o sentido de humanidade. A crítica aqui é dirigida expressamente à instituição familiar, que respalda o desregramento infantil, heroicizando o menino em suas artes de subjugar.

Como num álbum de retratos, datado do princípio do século XIX - recorde-se que os 64 anos de existência de Brás Cubas encerraram-se em 1869 - o texto vai liberando imagens sobre o lugar da criança no universo privado da família burguesa, inscrita sob o signo da ordem escravocrata. Pode-se pensar, nesse particular, na forma de convívio entre o menino Brás Cubas e Prudêncio, "um moleque de casa" que era para o primeiro o "cavalo de todos os dias". ${ }^{13}$ A animalização da criança vale como uma microcena do processo de anulação da dignidade dos indivíduos privados de liberdade. Em "Crianças escravas, crianças dos escravos", José Roberto de Góes e Manolo Florentino, tecendo comentários sobre a preparação dos filhos dos negros para o trabalho, assinalam:

O adestramento da criança também se fazia pelo suplício. Não o espetaculoso das punições exemplares (reservadas aos pais), mas o suplício do dia a dia, feito de pequenas humilhações e grandes agravos. Houve crianças escravas que, sob as ordens de meninos livres, puseram-se de quatro e se fizeram de bestas. ${ }^{14}$

Tudo isso assume uma dimensão ainda mais contundente, se examinado de um ângulo simbólico, uma vez que de há muito o cavalo de pau é uma representação metonímica da noção de infância. Em Jouets de toujours, ao esboçar uma caracterização para a ideia de infantia, tomando por base o pensamento da Idade Média, Michel Manson relaciona-a com a faixa etária correspondente ao período compreendido entre os três e sete anos, acrescentando ser ela "representada por uma criança pequena, com

\footnotetext{
${ }^{13}$ Idem, p. 526.

${ }^{14}$ GOÉS, José Roberto de; FLORENTINO, Manolo. Crianças escravas, crianças dos escravos. In: DEL PRIORE, Mary (Org.). História das crianças no Brasil. 2. ed. São Paulo: Contexto, 2000. p. 185-186.
} 
vestes longas, montada em seu cavalo de pau, com o bastão debaixo do braço, como uma lança". ${ }^{15}$

O próprio texto de Machado ratifica essa constatação, ao eleger o cavalinho de pau como uma eventual "alma exterior" do indivíduo, no conto "O espelho: esboço de uma nova teoria da alma humana", presente em Papéis avulsos (1882). "Há cavalheiros, por exemplo, cuja alma exterior, nos primeiros anos, foi um chocalho ou um cavalinho de pau", afirma Jacobina a certa altura da narrativa. ${ }^{16}$ Como o sintagma aludido é a base do esboço da teoria sobre o íntimo do indivíduo, tem-se que, a partir de "O espelho", a metamorfose perpetrada contra Prudêncio atinge-o em cheio, uma vez que a brincadeira em causa proporciona-lhe, efetivamente, uma identidade falhada da infância, já que o menino é impedido de ser sujeito de sua própria condição.

No romance referido, e ainda para caracterizar o Brás menino, Machado de Assis apropria-se da sentença "O menino é pai do homem", verso de Wordsworth (1770-1850), transformado em título do capítulo XI das Memórias, o que, dentre outros aspectos, revela o escritor, amigo de leituras inglesas. Esse verso, contido no poema "My heart leaps up", denota uma maior consistência dada ao mito da infância pela estética romântica, que passa a ler poeticamente a figura da criança como pura energia integrativa, tal como o fizera com a natureza. A raiz desse pensamento estaria em Rousseau, com sua teorização acerca da primeira idade no Emílio, ou da Educação, em que abre caminho para o nascimento do mito literário da infância, a ser explorado pelos pré-românticos, como ele próprio em Júlia ou a nova Heloísa: cartas de dois amantes habitantes de uma cidadezinha ao pé dos Alpes, em Emílio e Sofia, ou os solitários, obra inacabada, e, mais ainda, pelos autores do Romantismo.

Em "Eu sinto o coração bater mais forte", Wordsworth revela o estatuto ontológico atribuído à criança no período:

Eu sinto o coração bater mais forte.

Quando o arco-íris posso ver.

Assim foi quando a vida começou,

\footnotetext{
${ }^{15}$ MANSON. Michel. Jouets de toujours: de l'Antiquité à la Révolution. Paris: Fayard, 2001. p. 39. As traduções do francês são de nossa responsabilidade.

${ }^{16}$ ASSIS, Machado de. Obra completa, cit., v. 1. p. 526.
} 
Assim é agora quando adulto sou,

E assim será quando eu envelhecer...

Senão, melhor a morte!

O menino é pai do homem;

E eu hei de atar meus dias, cada qual,

Com elos da piedade natural. ${ }^{17}$

Especificamente no verso aforismático "O menino é pai do homem", ${ }^{18}$ o poeta configura um ideal: a permanência do espírito infantil, entendido como seiva vital, capaz de proporcionar a comunhão anímica do indivíduo com o cosmos. Ressalte-se a mensagem do sexto verso: "Senão, melhor a morte!" ("Or let me die!", no original) ratificando a intenção de que a busca do poeta liga-se à plenitude, uma vez que não a atingindo através da verdadeira vida, ou seja, da magia infantil, é preferível a morte, que, como não se desconhece, representa outra forma de vida para o romântico.

Nesse invulgar relato memorialístico - "Obra de finado" -, o perfil corrosivo do adulto já está demarcado na face traquinas do menino que foi Brás Cubas. "Desde os cinco anos merecera eu a alcunha de 'menino-diabo'!". ${ }^{19}$ Machado de Assis promove, aí, portanto, a subversão da avaliação sobre o mundo infantil efetuada por Wordsworth. Se, no poeta romântico, a infância é tomada como incessante fonte de renovação da experiência adulta, o escritor brasileiro faz do verso uma leitura de sobrecenho fechado, inoculando-lhe uma acentuada marca pessimista.

Aliás, o próprio anúncio do nascimento do personagem-narrador ("Naquele dia, a árvore dos Cubas brotou uma graciosa flor." ${ }^{20}$ já trouxera tensão à representação da infância como época primaveril, já que o sintagma "graciosa flor" tem o efeito cortante da ironia. Ironia que se apura, pouco adiante, na frase: "Lavado e enfaixado, fui desde

${ }^{17}$ WORDSWORTH, William. Poesia selecionada. Tradução de Paulo Vizioli. São Paulo: Mandacaru, 1988. p. 49.

${ }^{18} \mathrm{~A}$ fortuna do verso de Wordsworth ultrapassou os registros da arte, servindo de inspiração à teoria. Freud, como é sabido, valeu-se insistentemente da argamassa estética para a estruturação de sua teoria psicanalítica. Paul-Laurent Assoun transcreve uma frase do pai da psicanálise em que está presente o aqui já reproduzido verso de Wordsworth: "A psicanálise foi obrigada a derivar a vida psíquica do adulto da vida da criança, a levar a sério a proposição: o menino é o pai do homem". ASSOUN, Paul-Laurent. L'enfant père de l'homme. In: Penser/Rêver: le fait de l'analyse. L'enfant dans l'homme. Paris: Mercure de France, 2002. p. 89.

${ }^{19}$ ASSIS, Machado de. Obra completa, cit., v.1. p. 526.

${ }^{20}$ ASSIS, Machado de. Obra completa, cit., v.1. p. 525. 
logo o herói de nossa casa." ${ }^{21} \mathrm{O}$ conteúdo sarcástico dessa afirmativa somente será plenamente apreendido pelo leitor no acerto de contas que é "Das negativas", que se encerra, como já assinalado neste artigo, com um "pequeno saldo" para o herói: não ter feito brotar de si nenhuma "graciosa flor". Pode-se dizer, então, que o romancista, nessa passagem, não exclui a criança da agudeza de suas lentes hábeis em captar as deformações do espírito presentes nos indivíduos. A criação de um jogo de contrários, a partir da ideia de flor, impede a noção de infância de remeter ao frescor de pura seiva; pelo contrário, percebem-se no episódio notas de determinismo genésico, uma espécie de mácula original que, vinculada à criança, repercutiria no adulto: flor crestada, sem viço.

Estudando as múltiplas faces do fenômeno da intertextualidade, Tiphaine Samoyault utiliza uma metáfora vegetal para chamar a atenção para a forma como repercutem os ecos da criação artística:

Se cada texto constrói sua própria origem (sua originalidade), inscreve-se ao mesmo tempo em uma genealogia que ele pode mais ou menos explicitar. Esta compõe uma árvore com galhos numerosos, com um rizoma mais do que com uma raiz única, onde as filiações se dispersam e cujas evoluções são tanto horizontais quanto verticais. ${ }^{22}$

No caso em questão, o escritor brasileiro lança o verso sem identificar a fonte, apostando no repertório cultural de quem o lê, e espraia a significação original do enunciado, ao deslê-lo - jogando-o para o ar e deixando ao leitor a tarefa de apanhá-lo com outra significação - concretizando, como tal, a ideia mesma de rizoma: o título do capítulo valeria como um rebento aéreo brotado a partir do caule subterrâneo, cuja origem remontaria ao tempo da estética romântica.

A questão da não infância, sugerida pela ligação da criança com o trabalho, aqui já referida por intermédio de Prudêncio, é também verificável em "O caso da vara", conto que inaugura as Páginas recolhidas (1899), no qual Lucrécia, juntamente com outras amas da casa, incumbe-se do ofício de movimentar os bilros para a criação de

\footnotetext{
${ }^{21}$ Ibidem.

${ }^{22}$ SAMOYAULT, Tiphaine. A intertextualidade. Tradução de Sandra Nitrini. Revisão de Maria Letícia Guedes Alcoforado e Regina Salgado Campos. São Paulo: Aderaldo \& Rothschild, 2008. p. 9. Grifo do original.
} 
rendas, crivos e bordados. Além disso, o conto evidencia a qualidade do trato do adulto para com a criança, esta última experimentando uma continuada sujeição ao medo.

- Lucrécia, olha a vara!

A pequena abaixou a cabeça, aparando o golpe, mas o golpe não veio. Era uma advertência; se à noitinha a tarefa não estivesse pronta, Lucrécia receberia o castigo de costume.

Em um segundo momento, o narrador apela para um novo prisma de observação, qual seja, o registro, no corpo, da qualidade do tratamento recebido: "era uma negrinha, magricela, um frangalho de nada, com uma cicatriz na testa e uma queimadura na mão esquerda. Contava onze anos". A descrição física de Lucrécia é o retrato vivo de seu aniquilamento. Embora nela seja utilizado apenas um adjetivo, "magricela", todos os outros itens identificadores têm natureza valorativa e apontam para sua depreciação, o que se depreende da sequência de diminutivos que espelham sua existência lacunosa. A descrição, em seu final, aponta para um eu-adventício que se sobrepõe à sua identidade: "uma cicatriz na testa e uma queimadura na mão esquerda". (grifo nosso) Observe-se que a destreza da mão direita representaria a garantia da mão de obra doméstica.

A propósito, em "Corpos, detalhes e a narrativa humanitária", Thomas W. Laquer $^{23}$ chama a atenção para a simbologia do corpo dentro do romance e o sentido de comoção que as descrições que o envolvem como "locus da dor" podem despertar nos leitores. Em dado momento do ensaio, relaciona formas discursivas limítrofes, no que diz respeito ao assunto, a exemplo do romance, do relato médico e do inquérito parlamentar, salientando não haver "símbolo mais poderoso de degradação, nem uma estocada mais contundente na consciência moral entorpecida, do que a imagem da garotinha seminua que, subindo por um túnel escuro e estreito, empurrava uma carreta de carvão". Essa imagem teria figurado em um inquérito de 1842 acerca do trabalho infantil e feminino. Também de Lucrécia pode-se falar do corpo como um "locus da dor" e, a partir daí, repensar a posição de indiferentismo que algumas vezes é

\footnotetext{
${ }^{23}$ LAQUER, Thomas L. Corpos, detalhes e a narrativa humanitária. In: HUNT, Lynn. A nova história cultural. Tradução de Jefferson Luiz Camargo. São Paulo: Martins Fontes, 2001. p. 258.
} 
relacionada a Machado de Assis. A crueza da descrição do corpo da criança vale como um libelo contra práticas não humanitárias, de que a escravidão seria um exemplo cabal.

A história de Lucrécia, na verdade, é emoldurada pela de Damião, aspirante a padre por imposição familiar, que se vale do prestígio de Sinhá Rita, a dona da casa, junto a seu padrinho, e subsequentemente a seu pai, para ver-se de todo despido da batina, do roquete e da estola, indumentárias, para ele, opressoras. O narrador emparelha Damião e Lucrécia na condição de constrangimento, e o seminarista chega a experimentar um sentimento de simpatia pela menina, só que, ao final da narrativa, fala mais alto o interesse pessoal e Damião, mesmo sentindo-se compungido, entrega o instrumento de açoite a Sinhá Rita: "ele precisava tanto sair do seminário!"24

Alfredo Bosi enxerga em "O caso da vara" e em "Pai contra mãe" o delineamento do mal existente no sistema escravocrata brasileiro, que "nasce e cresce dentro de uma estrutura de opressão". ${ }^{25}$ Segundo ele, a vilania dos personagens, decorrente de seu instinto de autoconservação, deixa entrever uma forma sutil de esmagamento do outro exercida pelo homem pobre, ainda que juridicamente livre: "A essa condição ainda lhe resta usar do escravo, não diretamente, pois não pode comprálo, mas por vias travessas, entregando-o à fúria do senhor, delatando-o ou capturando-o quando se rebela e foge." 26

$\mathrm{Na}$ abertura de "Pai contra mãe" são anotados alguns dos instrumentos de suplício das práticas escravistas: o ferro ao pescoço, o ferro ao pé, a máscara de flandres, cada um com sua ciência própria na busca de impedir o exercício da dignidade pessoal dos cativos, representando o jugo na sua mais fiel expressão. Contudo, outras histórias do autor induzem à reflexão sobre o cotidiano das crianças livres, à época do Império. Seria o caso de se indagar: que distância separava a rotina massacrante dos pequenos escravos do cotidiano dos filhos das classes livres?

Nesse sentido, entra em cena a escola, com seus típicos instrumentos de silenciar: um deles, a palmatória, representação metonímica do poder punitivo. No "Conto de escola", de Várias histórias (1896), o narrador define-a por intermédio de um

\footnotetext{
${ }^{24}$ ASSIS, Machado de. Obra completa, cit., v. 2. p. 582.

${ }^{25}$ BOSI, Alfredo. O enigma do olhar, cit., p. 120.

${ }^{26}$ Idem, p. 121.
} 
símile aterrador: os "cinco olhos do diabo". Mesmo demonizada, entra em concorrência direta com a brutalidade dos mestres-escola, empenhados o mais das vezes na sequência incontornável do vigiar e punir. A expressão terrificante que salta de seus olhos e a aspereza da voz possuem, por um lado, efeito paralisante, instilado pelo medo, e, por outro, instigam a criança à dissimulação como tática de sobrevivência. Por tudo isso, a escola, nessa narração, vai significar preferencialmente um não lugar para as crianças machadianas.

Além disso, funciona como um palco e um estímulo para o exercício do cultivo das qualidades mesquinhas já em criança. O personagem-narrador da história revela um retrato de si mesmo sem retoques: "Não era um menino de virtudes." ${ }^{27}$ E o relato insiste em uma semântica do fingimento: são muitas mentiras, engodos, para com a mãe, para com o professor, tudo se encerrando na fuga consentida pela imaginação - a escola significava um estorvo, com suas regras inarredáveis. Não por acaso, a imagem aérea do papagaio se contrapõe à imagem estática dos bancos escolares, onde todos estavam presos como se fosse por grilhões.

Para cúmulo do desespero, vi através das vidraças da escola, ao claro azul do céu, por cima do morro do Livramento, um papagaio de papel, alto e largo, preso de uma corda imensa, que bojava no ar, uma cousa soberba. E eu na escola, sentado, pernas unidas, com o livro de leitura e a gramática nos joelhos. ${ }^{28}$

Não apenas a teatralização do professor, senhor do proscênio, acontece de fato. Em paralelo, outro jogo de poder enreda as crianças e cada uma delas lança seus dados. Raimundo, o filho do professor, seduz com a moedinha de prata; Pilar, por sua vez, tem como barganha a capacidade de ensinar; e Curvelo é o senhor do segredo entre ambos. Por meio do trio, destacado pelo ângulo da infância, percebe-se no "Conto de escola" a relação dinâmica entre o eu do indivíduo e o eu social, gerada a partir do espaço institucional, relação amparada na incorporação de uma enciclopédia de representações, cuja base é a intimidação. A descoberta da corrupção e da delação são as lembranças que vêm à memória do narrador, anos mais tarde, e resta como o capital de um tempo

\footnotetext{
${ }^{27}$ ASSIS, Machado de. Obra completa, cit., v. 2. p. 548.

${ }^{28}$ Idem, p. 550.
} 
sombrio, em tudo distante da imagem de beleza e inocência muitas vezes associada à criança e à infância.

Em "Umas férias", de Relíquias de casa velha (1906), novamente o estudo aparece como uma atividade enfadonha, mostrando-se capaz de suscitar na criança a criação de uma pedagogia da dissimulação:

Obrigado a estar sentado, com o livro nas mãos, a um canto ou à mesa, dava ao diabo o livro, a mesa e a cadeira. Usava um recurso que recomendo aos preguiçosos: deixava os olhos na página e abria a porta à imaginação. Corria a apanhar as flechas dos foguetes, a ouvir os realejos, a bailar com meninas, a cantar, a rir, a espancar de mentira ou de brincadeira, como for mais claro. ${ }^{29}$

É o Machado de Assis crítico que, ao escrever "A nova geração" (1879), reporta-se ao poema de Afonso Celso Júnior, fazendo-lhe uma observação sobre um aspecto algo inverossímel do texto:

A "Joia", aliás tão sóbria, tão concisa, parece-me um pouco artificial. Ao filhinho, que diante de um mostrador de joalheiro, lhe pede um camafeu, responde a mãe com um beijo, e acrescenta que esta joia é melhor do que a outra; o filho entende-a, e diz-lhe que, se está assim tão rica de joias, lhe dê um colar. É gracioso! mas não é a criança que fala, é o poeta. Não é provável que a criança entendesse a figura; dado que a entendesse, é improvável que a aceitasse. A criança insistiria na primeira joia; cet âge est sans pitié. ${ }^{30}$

A infância, "essa idade sem piedade". Trata-se de uma máxima enunciada por La Fontaine, nos longes do século XVII, transcrita em "Os dois pombos", em que o fabulista pinta um retrato realista da criança, no qual não hesita em colocar o risco sombrio da crueldade.

A simbologia poética atrelada aos pombos, além do tom elegíaco do poema uma espécie de meditativo de alguém em idade madura, que olha para trás e vê o tempo escoar -, é um alerta aos amantes no sentido de descortinar o infinito nos estreitos limites da convivência a dois. Em função da atmosfera do poema, torna-se ainda mais

\footnotetext{
${ }^{29}$ ASSIS, Machado de. Obra completa, cit., v. 2. p. 702.

${ }^{30}$ ASSIS, Machado de. Obra completa, cit., v. 3. p. 822.
} 
forte a agressividade da criança que, no texto, encontra seu par na ave de rapina. $\mathrm{O}$ poema, como o título adianta, gira em torno de um casal de pombos, que se separa em função do espírito de curiosidade de um deles, interessado em saber o que se esconde para além do beiral. O trecho em que é explicitado o comportamento da criança é:

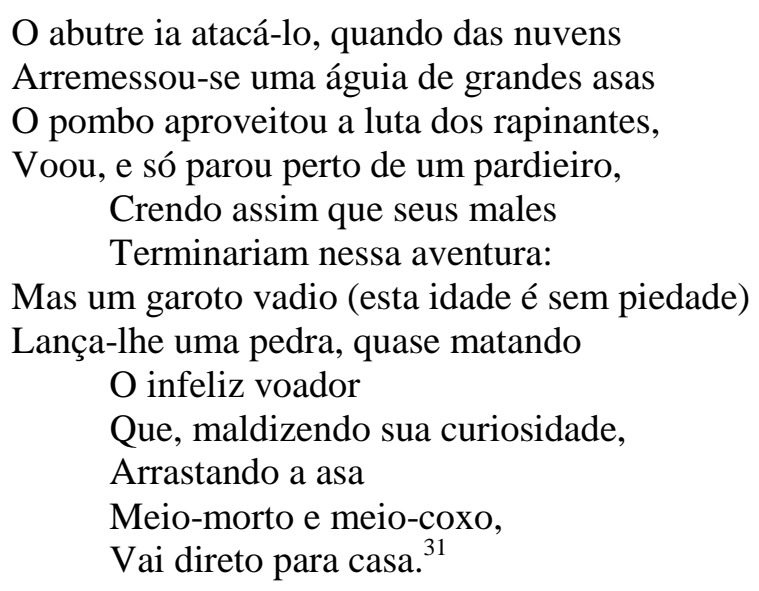

Em 1891, doze anos mais tarde, em Quincas Borba, o escritor novamente vai assinalar a crueldade infantil, ao descrever a sanha de um bando de crianças que se compraz em usar o espaço público, a rua, para criar uma algazarra derrisória em torno de Rubião. Rubião, que falava de si para si, dirigindo-se a já nem sabia a qual de suas imperatrizes - Eugênia ou Sofia? -, despertado pela algaravia - em que se destacava o coro infantil "- Ó gira! ó gira!" -, ${ }^{32}$ imaginava estar sendo saudado pelos passantes.

O escritor não poupou cores fortes para pintar o quadro da crueldade protagonizada por crianças, criando, inclusive, um personagem paradigmático nesse sentido: o pequeno Deolindo, salvo por Rubião do atropelamento por uma carruagem. É certo que a criança não o sabia, mas, ironicamente, guardou forte desgosto, como diria o próprio Machado, por não poder expressar seu pouco caso e desprezo por alguém tão risível.

Machado de Assis morre em 1908. Nesses mais de cem anos, o que, de fato, mudou com relação à compreensão do que seja a criança? Seus livros levam-nos a pensar sobre isso, induzidos que somos pela própria fermentação de ideias que deles

\footnotetext{
${ }^{31}$ LA FONTAINE. Oeuvres complètes. Paris: Éditions du Seuil, 1965. Tradução nossa.

${ }^{32}$ ASSIS, Machado de. Obra completa, cit., v. 2. p. 797.
} 
advém. Seria o caso de colocar em circulação as questões enunciadas por Antoine Compagnon, em seu Literatura. Para quêe: "Quais valores a literatura pode criar e transmitir ao mundo atual? Que lugar deve ser o seu no espaço público? Ela é útil para a vida?" 33

Os contos e os romances de Machado trazem ainda à baila questões cruciais, como a do peso histórico-cultural na formação dos caracteres humanos. Terá a vida social o poder de plasmar os "eus" que hoje somos, já a partir da infância? Ou, em outras palavras, que parcela restaria à individuação nesse processo?

E quanto aos espaços de sociabilidade, como a família, a escola e a rua: em que estágio de desenvolvimento no sentido da atenção ao dado humano estariam na contemporaneidade?

Machado, que, por muito tempo, foi tachado de alienado, no sentido de construir uma obra distanciada das contradições dos hábitos sociais de seu tempo, aparece, na verdade, quando lido com "olhos de perceber", como alguém que, seguro da potência da literatura, semeou histórias de que o leitor pudesse extrair sua visão sobre os seres e suas máscaras de convivência.

O tema da infância, vinculado à obra machadiana, revela-se produtivo, portanto, para ajudar no conhecimento de nossa humanidade: sinuosa, ambígua, alternando altos e baixos. E isso desde os tenros anos em que vive em nós o tempo de ser criança.

Referências:

ASSIS, Machado de. Contos recolhidos. Prefácio e organização de Raimundo Magalhães Júnior. Rio de Janeiro: Civilização Brasileira, 1956.

ASSIS, Machado de. Obra completa. Rio de Janeiro: Nova Aguilar, 1986. 3 v.

ASSOUN, Paul-Laurent. L'enfant père de l'homme. In: l'analyse. L'enfant dans l'homme. Paris: Mercure de France, 2002. Penser/Rêver: le fait de

\footnotetext{
${ }^{33}$ COMPAGNON, Antoine. Literatura. Para quê?. Tradução de Laura Taddei Bradini. Belo Horizonte: Editora UFMG, 2009. p. 20.
} 
BOSI, Alfredo. O enigma do olhar. São Paulo: Ática, 1999.

CAMPOS, Paulo Mendes. Meu reino por um pente. In: Crônicas escolhidas. São Paulo: Ática, 1981.

COMPAGNON, Antoine. Literatura. Para quê?. Tradução de Laura Taddei Bradini. Belo Horizonte: Editora UFMG, 2009.

GOÉS, José Roberto de; FLORENTINO, Manolo. Crianças escravas, crianças dos escravos. In: DEL PRIORE, Mary (Org.). História das crianças no Brasil. 2. ed. São Paulo: Contexto, 2000.

LA FONTAINE. Oeuvres complètes. Paris: Éditions du Seuil, 1965.

LAQUER, Thomas L. Corpos, detalhes e a narrativa humanitária. In: HUNT, Lynn. A nova história cultural. Tradução de Jefferson Luiz Camargo. São Paulo: Martins Fontes, 2001.

LE BRETON, David. Ritos de intimidade. In: CAHEN, Gerald (Coord.). O beijo: primeiras lições de amor, história, arte e erotismo. Tradução de Ana Matilde de Mesquita Sampaio. São Paulo: Mandarim, 1998.

MANSON. Michel. Jouets de toujours: de l'Antiquité à la Révolution. Paris: Fayard, 2001.

SAMOYAULT, Tiphaine. A intertextualidade. Tradução de Sandra Nitrini. Revisão de Maria Letícia Guedes Alcoforado e Regina Salgado Campos. São Paulo: Aderaldo \& Rothschild, 2008.

TELLES, Lygia Fagundes. Apresentação de Machado de Assis. In: SECCHIN, Antonio Carlos; ALMEIDA, José Maurício Gomes de; SOUZA, Ronaldes de Melo e (Orgs.). Machado de Assis: uma revisão. Rio de Janeiro: In-Fólio, 1998.

WORDSWORTH, William. Poesia selecionada. Tradução de Paulo Vizioli. São Paulo: Mandacaru, 1988.

Fernanda Coutinho, doutora em Teoria da Literatura pela Universidade Federal do Ceará, é professora do curso de Letras e do Programa de Pós-Graduação em Letras da mesma universidade. Entre suas produções mais recentes estão: "Conversas com Dear Mimmy: imagem da criança escritora na contemporaneidade ou a difícil tarefa de entender a guerra", em Itinerários (Araraquara: UNESP, 2011); "Da terra e do céu, a poesia que vem dos bichos: Manoel de Barros e suas memórias inventadas", em Aletria (Belo Horizonte: UFMG, 2011); e "Pequeno dicionário de sedução: o lugar dos objetos na vivência do amor", em Machado e Rosa: leituras críticas, organizado por Marli Fantini (São Paulo: Ateliê Editorial, 2010). E-mail: <fmacout@terra.com.br>

Recebido: $15 / 09 / 2011$

Aprovado: 21/11/2011 